\title{
Construction of power production safety management
}

\author{
Ling Wang \\ Benxi Power Supply Branch, State Grid Liaoning Electric Power Supply Co. Ltd \\ Benxi, china \\ bxwl_wl@163.com
}

\begin{abstract}
Power industry is one of our basic industries, the development of the national economy and national security as well as energy has a very close relationship, and with the continuous development and progress of society, the status of the power industry is becoming increasingly important. However, in the power industry in the production process, there is an important and very worth considering is the production of security management. As we all know, to achieve the maximum benefit of the enterprise foundation is safety, if a security incident, it will have to reduce external power supply, increase the variety of expenses, the result is to make the rising cost of doing business, economic decline, and the personal safety of enterprise workers have to less than reliable guarantee, therefore, the power companies, strengthen safety management work is necessary. In this paper, the concept of power production from its scope, analyzes the common problems of electricity production and performance, build power production safety management, and discuss measures to strengthen the new power production safety situation management.
\end{abstract}

Keywords- power production; management; FAQs; building

\section{INTRODUCTION}

The power industry is related to people's livelihood, the party and the country's image on the basis of industry, with daily life and its economic and social development of the people are closely related. Provide a reliable and stable supply of electrical energy is the primary task of enterprises, but due to the high risk industries, systems technical complexity of production safety features to bring a lot of problems. On the other hand, with the deepening of the reform of China's power and changes in market supply and demand, power companies began to shift to the customer service-oriented enterprises.[1] How to maintain a competitive advantage in the supply of this transformation, one important point is to establish a good supply project safety management mode, with the system and ensure safety in production mode. Safe production is the cornerstone of the survival and development of electric power, it not only affects the enterprise's own internal and external can thus image, but also to improve the basic premise of supply service quality and customer satisfaction. In our economy and society is in a good period of rapid development, power production safety management is particularly important[2-3]

At present, China's power industry has entered a large grid, high-voltage, long-distance era. But also to the rapid development of safe and stable operation of the power system brings a new, more problems and challenges, how to deal with and solve these problems and challenges become power supply enterprises must be addressed[4]. In addition, China's power industry, there are still government on the industry standard management functions of weakening, the corresponding industry standards is not enough time, the construction of power daily entry of construction safety management difficult to monitor and so many problems. These issues have hampered the rapid supply enterprise harmonious and sustainable development[5-6]. In this new situation, power companies have to study new situations and solve new problems. Therefore, the power project safety production management research has great theoretical and practical significance, is conducive to the sustainable development of power prices.

\section{THE CONCEPT OF POWER PRODUCTION SAFETY AND FAQS}

After the rural power system, to bring pressure on the safety management. After the rural power system, the power sector separating the original power supply bureau corporatization and restructuring of commercial operation, that is no longer the exercise of governmental power sector tube electric administrative functions. Management responsibilities has also undergone a major transformation of the agricultural electrician unified incorporate not only the safety of agricultural electrician into a power range of enterprise security management, rural people is the possibility of personal electric shock casualties, power companies can not escape the stakeholders, so that the power supply enterprise shoulder The burden even heavier. In production, heavy construction tasks, the relative shortage of personnel, the ability to grasp and control the safe production declined, basic safety position has been weakened, a certain degree of confusion exists on the site of production organization[7]. Under particularly heavy task in the current power grid construction and transformation, tight, long front, demanding situation, focusing on the rush period, grab the task, the relative neglect of safety production, signs of the accident, security risks to be breeding in the law to protect the facility on safety oversight measures ineffective, resulting in inadequate security management. Cable lines, communication lines and power lines with pole erection; project legal agreements and design, supervision, construction and other parties entered widespread irregularities.

Power companies have always implement semi-militarized management, the implementation of "a veto" on safety in 
production. Production safety should be very productive. But there are some common issues can not be ignored. Advance the prevention and control things enough process, safety management is not really pass forward, workflow is unclear, there is no real standardization work carried out, the team and the job site confusion, site security measures in place, organizational relationships confusion. At the production site, serious violation popular phenomenon, unimpeded, field work responsible careless, irresponsible, and more serious problems jobsite team. Meanwhile, the Electric Power Bureau in safety management at present, there still exist problems of safety management formalism[8]. Extensive management of the phenomenon has not completely changed management process randomness, there are chapters that do not follow and buckpassing phenomenon still exists, strict work style and strict management of the atmosphere has not been widespread formation. There are strict requirements for front-line workers, strict examination, the presence of loose, loose, soft, lax work style problems, leading to the management of landslides. The existence of lax enforcement, lost in the soft.

Because of the power supply enterprise safety supervision department fewer personnel, lack of expertise, production safety supervision and management functions not been fully exploited, often wrapped some unproductive affairs investigation after the accident and liability accustomed to pursue. In recent years, rural electricity supply enterprise facilities occur stolen devastation more. Stealing caused great loss to the community and power companies.

The most fundamental safety production, the most important factor is that people who are key to the quality of production safety, safety in the production process is the most active factor. According to statistics, more than $90 \%$ of the main reason for the accident because of people's unsafe behavior, caused by violation of safety regulations. I believe that most of the power supply Power Administration and businesses, people's unsafe behavior in employees mainly produce poor security responsibilities to fulfill, consciously abide by safety procedures, the intensity of regulations, rules and methods of inadequate professional skills, cultural qualities and management skills can not fully meet the needs of the enterprise more complaints, request more, requiring more and more criticism of corporate loyalty is not high enough gratitude, dedication weak, less rationalization proposals, and the signing and implementation of a mere formality labor contracts, staff only to enter, not out, to protect the poor, inefficient people, blow up the excellent, advanced employee motivation and so on. This aspect is the issue of human resource development, and on the other hand the most fundamental institutional issues or corporate security ideological confusion, security responsibilities may not be implemented. Lax safety awareness, paralysis of thought on the rise. Because of safety in production in a long time in a stable state, cadres, workers appeared safe production paralysis of thought and emotion lax on safety in production of long, arduous, periodic, recurrent lack awareness, vigilance eased, a sense of crisis has been indifferent, objectively lead to the implementation of the rules and regulations and lax management of landslides and other issues, and is an isolated phenomenon, but has a certain universality. Electricity producers have developed a series of production safety system, also clearly safe production duties, but the following problems: 1) responsibility for the safe production may not be implemented, just stop speech in a meeting, only a general, principled mobilization . 2) leadership in charge of the production of the busy transactional work, no in-depth investigations and studies, little analysis of the unit of production safety problems do not develop appropriate corrective measures. 3) authorities will inform superiors forwarded a turn of the accident, neither careful analysis, nor propose and implement preventive measures. Power production safety professionals do not really know what to do, do not master the necessary procedures system, not a good team to guide the grass-roots work.

Unsafe industrial equipment management confusion, there are some security risks using the appliance quality and safety workers worrying. In particular, the quality of the pass rate of climb some power equipment and other safety equipment for the job is not high. Meanwhile, regular testing of security appliances consciousness, scrap management a mere formality. Strictly implement the "safety", often habitual violation habitual violation is designated for granted safe production work of the violations occur frequently. It includes illegal operations, illegal command and violation of labor discipline. Some temporary work, such as a distribution repair personnel, fill in the absence of repair tickets start repair work, leading to physical shock fatalities; some jobs require power, in the absence of electricity, electrical inspection, hanging under the ground situation, began to work, resulting in personal electric shock fatalities; transformer secondary knife when dealing with poor contact failure, there is no power to change stations, electrical inspection, not hanging ground, illegal operations and lead to serious personal electrocution fatalities and more.

\section{CONSTRUCTION OF POWER PRODUCTION SAFETY MANAGEMENT MODEL}

In electricity production management, power production safety management is an important element, its level for electricity production as well as its economic efficiency have a very important role. However, at present, electricity production process, there are some problems that affect the economic benefits of increased electricity companies, therefore, under the new situation, how to manage power production safety work to strengthen, is a very worthwhile considering. To fully understand the importance of safety management

To meet the basic national conditions of China's power development, and adaptation of electricity production major security requirements of our national power company with the provincial power company related safety requirements, a number of electric power companies must close contact with the actual formulation of the appropriate combination of power production safety situation and the actual unit measures to improve the management and then, ultimately makes the electricity companies to maximize efficiency. Electricity is the basic industry of national economic development, and economic and social development has been people's lives, building a harmonious society habitat and relates to the development and stability of society as a whole, electricity production enterprise security has become increasingly prominent role and significance, to achieve power enterprises 
safety, there must be a set of safety management systems, standards, rules, work instructions, etc. to regulate, regulate people's behavior, standardize equipment operational processes and procedures, it is necessary to insist on carrying out habitual anti-illegal activities. System with iron, iron faces, iron deal with anti illegal command, illegal operations, in violation of labor discipline. The second is to comprehensively promote the standardization work site. Standardized field operations procedures, the implementation of on-site security measures to ensure that on-site production process control, in control, in order to avoid heavy casualties and grid accident.

\section{A. Strengthen mechanisms to improve the management level}

With a wealth of net plant and power production enterprises capital formation, requirements and content of corporate security management also changed; and power grid construction and accelerate the construction of power rate, but also led the direction of the power supply and demand contradictions generated transfer, human social life of the power quality requirements continue to increase, making the impact of electricity production is very significant incident, security incident handling to the legalization of the direction of change; after electricity production enterprises into commercial operation, how to solve the efficiency and safety The relations. These, in the objective we must require electricity enterprise security management thinking and careful analysis, to ensure the safe operation of the new system of electricity production. Electricity production enterprise security management is a systematic work, a very wide range of their work, usually involving various departments, various departments, are often able to relate to all the staff of power companies, special attention is generally safe production and liability management is in place related to its work efficiently if the key is to take the lead in the power sector business leaders. Therefore, the actual power production work, the power companies must pay attention to the construction of power production safety responsibility system, and strictly implement the leadership of each department should do related work, while clear objectives of safety management in order to achieve the entire enterprise joint management of safety production management pattern.

To establish a mechanism for continuous improvement, give prominence to the safety evaluation of dynamic management. To establish emergency warning mechanism to strengthen the safety management of the whole production process, in accordance with the "hierarchical management, rectification" principle, there are security risks for the sector, and promptly rectification in place. To improve the management mechanism, strengthen basic management. Earnestly national grid company "electrical safety work order" and other regulations, standards, training and implementation. To strengthen the supervision and evaluation, improvement and restraint mechanisms, effective implementation of safety oversight responsibilities. Safety supervision and management to achieve the "three in place", thinking and understanding should be in place, oversight responsibilities should be in place, the basic work should be in place at the same time to strengthen the "four kinds of consciousness", namely: service awareness, strict sense of coordination consciousness, innovation. Improve safety supervision functions and staffing, strengthening rural power production safety supervision and management. Adhere to start from the foundation, sooner, center of gravity, good job supervision and management of the site.

\section{B. Implementation of safe production responsibility at all levels}

To carry out a full range of safe production, the whole process management, continuous improvement and the establishment of safety management system. Adhere to administration of the first head of the first responsibility is the security system, set production targets and safety plan, lines, equipment zoning to lines and distribution transformer station area as a unit, down to every level of the security responsibility to the people, the implementation of various level contract. And rural power supply enterprise management, rural power management and powered by, powered by the rural electrician, signed their "safe production target of responsibility", the "security risk deposit system", the formation of safe production at every level , primary-level security situation, the assessment indicators linked with the department, team and individual economic interests, to really make safety management in the end to form a vertical, horizontal-to-edge, full, comprehensive, a new pattern of the whole process of management. It should also be well informed of the compilation of accident, incident reporting compilation is the lesson of blood, is the accumulation of experience and lessons learned, we must seriously study the organization of all employees, by analogy, in order to prevent the occurrence of repeated accidents. Responsibility for production safety traceability system implemented in the enterprise of accidents and near misses occur, we must act in principle "Three left off" will be dealt with severely. Power production safety management must adhere to the principle of treating the symptoms, and improve employee awareness for safety in production, and actively take various measures to prevent the emergence of electricity production in a variety of issues. In addition, also for electricity production corresponding supervision, thereby promptly discover and resolve the problem so that power production safety management level greater increase.

With the continuous development of the power industry, its security incidents in the production process more and more performance out of responsibility for security incidents are becoming more complex. Therefore, in order to secure production and meet the requirements, we must adjust and modify the existing power production safety laws and regulations. SERC should fully listen to the views of the power companies on the basis of the relevant departments to conduct electricity production experience safe summary of the relevant laws positively perfect. In the course of the preparation of power-related laws and regulations, and to fully reflect the relevant content and power production safety supervision and management, so that management can power production safety of law.

\section{Strengthening quality management of safety equipment}

Due to further improve social productivity, development and technological level of China's power enterprises is also rising, and the same as other professional disciplines, safety 
ergonomics discipline also needs to be supplemented with further improvement of the power companies must adhere to the past and proved to be feasible continue to make security management on safety management more scientific and constitution of, for example, the establishment of standardized power enterprise security management procedures in order to reduce accidents, to regulate the behavior and habits of workers to carry out frequent irregularities and illegal Points assessment measures to ensure the safety management standardization final run. Demanding industrial equipment scrapped system. Expired, has been damaged and defective industrial equipment all to mandatory retirement. To prohibit any form of industrial equipment has been scrapped for resale (rent) to other business or personal use. To develop and implement standardized safety equipment maintenance management system. For industrial equipment, materials needed, repair and test records, inspection records should be made specific and detailed provisions, so well documented, the responsibility to implement.

Standardized field operations procedures, the implementation of on-site security measures to ensure that onsite production process control, in control. Site security measures to strengthen the standardization of management. Site security technology to ensure the implementation of measures to improve the prevention and control of human error level. Increase staff training efforts. There are plans to organize learning.

\section{CONCLUSION}

In summary, the deepening of the reform of the power system, making electricity production safety management more and more people's attention, but in the actual power production safety management work, just need to practice and the development of the electricity reform continue to explore, continue to accumulate work experience, but also need the support and cooperation of the relevant government departments and the community. By talking about the importance of safety work, learn safety procedures, talk about the lessons of safe production, test production safety rules and other means to enhance the safety awareness of employees. Under different circumstances, the power companies have different security management measures, only increasing safety supervision, strict implementation of safety production incentive regulations, strict accountability system for major accidents, efforts to improve the level of scientific management of power production, in order to ensure safe production implement the requirements in the new situation, for power production safety management to reinforce the need to improve the construction of electrical safety regulations and systems, increasing the intensity of safety oversight, incentives for production safety regulations must be strictly execution, and actively cultivate the overall quality of electricity production safety of workers, in order to achieve the goal of safe production of power.

\section{REFERENCES}

[1] R.H.Williams, “ Toward zero emissions from coal in China,” Energy for Sustainable Development,vol. 5,pp. 39-65, 2001

[2] Erdem, H.H., Akkaya, A.V., Cetin, B., et al. , “ Comparative energetic and exergetic performance analyses for coal-fired thermal power plants in Turkey," International Journal of Thermal Sciences,vol. 48,pp. 21792186, 2009

[3] Kumar, R., Mahur, A.K., Sengupta, D., Prasad, R. , “ Radon activity and exhalation rates measurements in fly ash from a thermal power plant," Radiation Measurements,vol. 40,pp. 638-641, 2005

[4] Gu, D.X., Liang, C.Y., Li, X.G., et al. , "Intelligent Technique for Knowledge Reuse of Dental Medical Records Based on Case-Based Reasoning," Journal of Medical Systems,vol. 34,pp. 213-222, 2010

[5] Harman, D. , “ Evaluation issues in Information Retrieval, " Information Processing \& Management,vol. 28,pp. 439-528, 1992

[6] Hongtao D, Jianhong X, "Safety management system of construction enterprise performance," J Saf Sci Technol,vol. 4,pp.108-110, 2008

[7] Du R, Jia L, “ SPSS statistical analysis from entry to master,” Posts and Telecom Press,vol. 3,pp.120-132, 2009

[8] Wen Z, Hau K, Marsh HW , "Structural equation model testing: fitting index and Chi square," J Psychology,vol. 36,pp. 186-194, 2004 